\title{
LA AMISTAD COMO PRINCIPIO DE LA POLIS*
}

\author{
GonZalo Letelier Widow** \\ Pontificia Universidad Católica de Chile, Chile \\ gletelier@santotomas.cl
}

\begin{abstract}
RESUMEN: La filosofía política y jurídica de la modernidad (el énfasis será en Hobbes, Rousseau, Kant y Rawls) se ha caracterizado por asumir hipotéticamente la insociabilidad del hombre como punto de partida de su construcción de una teoría de la sociedad. En su forma más pura, esta "antropología negativa" toma la forma de un "estado de naturaleza" en virtud del cual el problema de la teoría política es unir en sociedad a individuos egoístas e insociables y conciliar la libertad con la ley. La perspectiva clásica es radicalmente diversa, pues se funda en la natural sociabilidad del hombre que, en concreto, supone afirmar que los hombres se asocian en virtud de una forma mínima y natural de amistad útil, que constituye la homonoia o concordia de la polis, fundamento de toda comunicación social y de toda justicia. El artículo termina respondiendo eventuales objeciones y enunciando algunas consecuencias de este cambio de perspectiva.
\end{abstract}

Palabras clave: Amistad, politica, sociedad, Estado, antropología negativa.

\section{FRIENDSHIP AS A POLIS PRINCIPLE}

\begin{abstract}
Modern political and juridical philosophy (specially Hobbes, Rouseeau, Kant and Rawls) has hypothetically assumed the unsociability of man as a premise for the construction of a theory of society. In its purest form, this "negative anthropology" assumes the form of a "state of nature", so the main problem of political theory is to unite in society selfish and unsociable individuals and to reconcile freedom with law. The classical perspective is radically different, as it is based on the natural sociabi-
\end{abstract}

El texto corresponde a la relación presentada en el $V$ Congreso de Teoría Constitucional organizado por los estudiantes de la Facultad de Derecho de la Universidad de Chile entre el 16 y 19 de agosto de 2011. Trabajo recibido el 23 de enero y aprobado el 15 de marzo de 2012.

** Director del Centro de Estudios Tomistas, Universidad Santo Tomás, Profesor de Filosofía del Derecho, Pontificia Universidad Católica de Chile. 
lity of man. This means that men associate one another because of a minimal and natural form of friendship, which constitutes homonoia or concord of the polis, base and condition for every form of communication and justice. The article concludes by answering some objections and stating some consequences of this change of perspective.

Keywords: Friendship, politics, society, state, negative anthropology.

En toda comunidad hay una cierta forma de justicia y de amistad ${ }^{1}$ Existe una forma de amistad para cada tipo de constitución, en la medida en que hay también justicia ${ }^{2}$

\section{1. "AMIGOS, YA NO HAY AMIGOS"3}

La paradójica afirmación de Aristóteles que da título a esta primera sección admite múltiples lecturas. Respecto de nuestro problema, me parece que ella describe adecuadamente la aporía del "modo moderno" de la filosofía política y, particularmente, al liberalismo contractualista de Kant y Rawls.

El valor de la frase está en que manifiesta eficazmente la paradoja de una afirmación que resulta inteligible sólo en la medida en que el interlocutor a quien se dirige perciba que es actualmente falsa, al modo de uno que dice a otro "no estoy hablando contigo". Aristóteles puede lamentarse de que ya no existen amigos porque todavía hay amigos que lo escuchan.

La tesis de este trabajo es que esta paradoja es la misma que atraviesa a la filosofía política fundada sobre el principio del estado de naturaleza.

Dicho en otros términos, sólo es viable proponer una filosofía política fundada en la metódica e hipotética negación de la amistad entre los hombres en la medida que en se acepte, de contrabando y contra las propias premisas, que los hombres son amigos y que es precisamente por eso que existe la sociedad.

Una teoría política fundada en la discordia es posible y concebible en la precisa medida en que una sociedad real fundada en la discordia no lo sea.

1 Aristóteles, Ética Nicomaquea, VIII, 1159b 25. En: Aristóteles. Le tre etiche. Milano, Italia: Bompiani, 2008. Vid también Platón. República, Madrid, España: Gredos, 1992, IV, 424a y Cicerón, De Legibus, I, 12, 33. En su: Sobre la República y Sobre las leyes. Madrid, Espańa: Akal, 1989

2 Aristóteles, Ética Nicomaquea, op. cit. (n.1) VIII, 1159b 25VIII, 1161a 10.

3 La cita corresponde a la biografía de Aristóteles de Diógenes LaErcio, Vida de los filósofos ilustres, V (se tiene presente la siguiente edición: Vite e dottrine dei piú ilustri filosofi. Milano, Italia: Bompiani, 2005). La frase ha sido citada y utilizada, con los más diversos sentidos, por Montaigne (Ensayos. Madrid, España: Cátedra, 2005, I, 27), Kant (Cf. Lecciones de Ética. Barcelona, España: Crítica, 2009, donde la atribuye a Sócrates, y los lugares paralelos allí citados), Nietzsche (Humano, demasiado humano. Madrid, Espańa: Akal, 1996) y Derrida, Jacques. Politiques de la amitié. Paris, Francia: Galilée, 1994), entre muchos otros. 


\section{I.I. LA PREMISA CONTRACTUALISTA}

El punto de partida todas las formas del contractualismo moderno es la negación metodológica de toda forma de sociabilidad natural, incluyendo, a fortiori, la amistad. En esto consiste el estado de naturaleza; en eso también el velo de ignorancia de Rawls. En realidad, esta hipótesis, con otros nombres y bajo otra apariencia, es coesencial a las teorías jurídicas que normalmente han sido denominadas "iuspositivistas" y a todas aquellas que, más allá del nombre que reciban o se atribuyan a sí mismas, consideran la sociedad política de los hombres como un artificio modelado según su propia voluntad. Así, por ejemplo, sería difícil hallar un "estado de naturaleza" en la doctrina de Kelsen o en el realismo jurídico escandinavo, y sin embargo, tanto en un caso como en el otro, el principio de la insociabilidad humana se mantiene vigente y operante bajo la forma de una sistemática indiferencia de la teoría jurídica por los motivos de la acción, indiferencia que coincide funcionalmente con una afirmación positiva de la insociabilidad natural. Tal como para los clásicos del contractualismo moderno, la cuestión relevante no es que el hombre sea, de hecho, insociable por naturaleza (¿qué es "naturaleza”?), sino que la filosofía jurídica y política debe considerarlo como si lo fuera ${ }^{4}$.

En expresa analogía con el concepto moderno de ciencia empírica, para los contractualistas el estado de naturaleza hace las veces de una hipótesis científica ${ }^{5}$; un principio asumido convencionalmente como verdadero en cuanto permite dar respuesta a ciertos problemas operativos. El tema fue estudiado profusamente por el profesor patavino Francesco Gentile ${ }^{6}$. Nos limitaremos a señalar dos aspectos particularmente recurrentes en estos autores. Por una parte, la estructura hipotético-deductiva del conocimiento, caracterizado por la aspiración a la certeza, exactitud y previsibilidad de sus conclusiones, estructura de la cual la ciencia del derecho debe participar si quiere ser ciencia. En segundo lugar, el clásico principio inspirado en Bacon: scientia propter potentiam ${ }^{7}$. De aquí, por ejemplo, la idea del derecho entendido como técnica de control social, cuando no directamente como principio de redención intrahistórica.

4 Este carácter hipotético y pragmático parece estar claro ya en MaCHIAVELLI, quien sostiene que el príncipe debe considerar a todos sus súbitos como si fueran malos ("Come dimostrano tutti coloro che ragionano del vivere civile, e come ne è piena di esempli ogni istoria, è necessario a chi dispone una republica, ed ordina leggi in quella, presupporre tutti gli uomini rei, e che li abbiano sempre a usare la malignità dello animo loro, qualunque volta ne abbiano libera occasione", en sus Discorsi sopra la prima deca di Tito Livio, I, 3)

5 Thomas Новвеs, por ejemplo, intenta demostrar su plausibilidad, pero no se ocupa de su historicidad. Es el sentido de los ejemplos citados en el capítulo 13 del Leviathan: los salvajes de América, la guerra civil y las relaciones internacionales entre Estados igualmente soberanos (Cfr. The English Works of Thomas Hobbes of Malmesbury; Now First Collected and Edited by Sir William Molesworth. Londres, Reino Unido: John Bohn, 1839-1845, vol. III, pp. 114-115; en adelante, se citará simplemente "EW" seguido de volumen y página).

6 Cfr. en particular Gentile, Francesco. Filosofia del Diritto (le lezioni del quarantesimo anno raccolte dagli allievi). Padova, Italia: Cedam, 2006 e Inteligencia política y razón de Estado. Buenos Aires, Argentina: EDUCA, 2008.

7 Cfr. T. Новвеs, De Corpore, c.1: "Scientia propter potentiam; Theorema (quod apud Geometras proprietatis investigatio est) propter problemata, id est propter artem construendi; omnis denique speculatio, actionis vel operis alicujus gratia instituta est utiiitas" (en Thomae Hobbes Malmesburiensis Opera Philosophica quae Latine scripsit Omnia, in unum corpus nunc primum collecta studio et 
En este contexto, la función de la filosofía política moderna no es explicar la sociedad según lo que ésta necesariamente es, sino fundar la sociedad justa. Y para fundarla es útil hacer cuenta de que la sociedad tal como la conocemos no existe y suponer que el individuo no vive necesariamente en sociedad, procediendo posteriormente a construirla desde cero.

En Kant (y en Rawls, su discípulo declarado) esta hipótesis asume un carácter peculiar: pretende dejar de ser por completo una tesis antropológica, deviniendo puro principio metodológico abstracto. Hobbes, Grocio, Pufendorf, Locke, e incluso Rousseau, fundaban todavía la sociedad en aquello que veían como consustancial al hombre. Pero ya Rousseau notaba y criticaba el error de este método: el hombre que conocemos no es el hombre natural, sino el hombre producido por la sociedad, el cual no puede constituir otra sociedad diversa de aquella sociedad aberrante en la que de hecho vive 8 . En efecto, para Rousseau "l'homme naturel est tout pour lui; il est l'unité numérique, l'entier absolu, qui n'a de rapport qu'à lui-même ou à son semblable" . A diferencia del hombre de Hobbes o de Locke, l'homme de Rousseau no es anti social ni pre social; es absolutamente asocial; la sociedad de los hombres, por lo tanto, no debe ser corregida, sino sencillamente refundada, para lo cual es necesario cambiar su naturaleza ${ }^{10}$, destruir por completo el homme para crear de la nada al citoyen. Si bien establece las premisas para la idea de "hombre abstracto" de la doctrina política posterior, la hipótesis rousseauiana del buen salvaje conserva todavía, sin embargo, ciertas propiedades de un mito originario al modo platónico, y de este modo, sigue anclada en la antropología ${ }^{11}$.

labore Gulielimi Molesworth. Londres, Reino Unido: Joannes Bohn - Longman, Brown, Green et Longman, 1839-1845, vol. I, p. 6; en adelante "OL"). Pese a que nunca lo reconoció abiertamente, la influencia de sus estudios con Francis Bacon es difícilmente discutible.

8 La afirmación más clara se encuentra en el fragmento État de guerre, dedicado precisamente a distinguir el estado de naturaleza del estado de guerra: "Je l'ai déjà dit et ne puis trop le répéter, l'erreur de Hobbes et des philosophes est de confondre l'homme naturel avec les hommes quils ont sous les yeux, et de transporter dans un système un être qui ne peut subsister que dans un autre" (VAUGHAN, Charles Edwyn. The Political Writings of Jean-Jacques Rousseau. Cambridge, Reino Unido: Cambridge University Press, 1915, vol. I, p. 306; en adelante, "PW" seguido del volumen y la página). Rousseau critica duramente a Hobbes en la primera parte del Discours sur l'origine et les fondements de l'inegalité parmi les hommes, en el Contrat Social, I, IV y en el fragmento citado (État de guerre); en este último, con tono directamente ofensivo: se trata de un "horrible système" (Ibíd., PW, I, p. 305), "aussi revoltant qu'absurde, qui a déjà cent fois été réfutê" (Ibid, p. 294). El mismo Hobbes no es más que un sofista (Ibid, p. 293 y 306). Pero al mismo tiempo y en la misma obra (de hecho, en el mismo párrafo), Hobbes es "un [des plus grands philosophes et] des plus beaux génies qui aient esistê" (Ibid, p. 305). En efecto, la influencia de Hobbes en Rousseau es mucho más profunda de lo que puede parecer a una primera lectura (cfr. Derathé, Robert. Jean-Jacques Rousseau et la science politique de son temps. Paris, Francia: Vrin, 1988). Según VAughan ("Introduction" al Contrat Social, PW, II, p. 9) su deuda respecto de Hobbes y de Grocio, quizás los dos autores que más duramente critica, es "at least as much of rejection as acceptance". Vid. también Morel, Jean. "Recherches sur les sources du Discours sur l'Inégalité", Annales de la société J.-J. Rousseau, No 5, (1909), pp. 119-198, p. 160.

9 Émile, I; cfr. PW,II, p. 145.

10 Cfr. en particular, Contrat Social, II, VII, PW, II, p. 51-52: “Celui qui ose entreprendre d'instituer un peuple doit se sentir on état de changer pour ainsi dire la nature humaine, de transformer chaque individu, qui par lui-même est un tout parfait et solitaire, en partie d'un plus grand tout, dont cet individu reçoive en quelque sorte sa vie et son être".

11 Para el estudio de la versión rousseauiana del estado de naturaleza resulta indispensable el análisis desde la siquiatría realizado por Jean Starobinski. Cf. sobre todo La trasparence et l'obstacle. Paris, Francia: Gallimard, 1971 y "Jean-Jacques Rousseau et le péril de la réflexion”, en: Annales de la Société Jean-Jacques Rousseau, n³4 (1956-1958), pp. 139-174, republicado después en L'Oeil vivant. Paris, Francia: Gallimard, 1961. 
Kant, siendo profundamente rousseauiano ${ }^{12}$, recoge esta tesis y la lleva un nivel superior de abstracción, haciendo del estado original una idea de la razón ${ }^{13}$. El Rawls de la Teoría de la Justicia, finalmente, pretende haber concluido este proceso abstractivo ${ }^{14}$. En efecto, supuesta la "gran división" entre conocimiento práctico y especulativo, entre "is" y "ought", entre "sein" y "sollen", no tiene ya sentido pretender fundar la filosofía práctica en tesis antropológicas con pretensión de verdad. La libertad, como el alma, son en el orden práctico simples postulados indemostrables; son las hipótesis que hacen posible la ciencia práctica ${ }^{15}$. Lo mismo sucede con el estado de naturaleza, que es el supuesto necesario para postular el contrato como Idea de juridicidad $^{16}$. De idéntico modo, la justicia como equidad es política, no metafísica, según el título de un famoso artículo de Rawls ${ }^{17}$.

La cuestión se hace particularmente evidente cuando se considera la progresiva formalización de la virtud de la justicia, cuya obligatoriedad es cada vez menos jurídica y más moral. En efecto, en estos tres eslabones teóricos (Rousseau, Kant, Rawls) la justicia está cada vez menos referida al otro en cuanto tal; su objeto y motivo no es ya el ius en cuanto "suum cuique", es decir, el bien ajeno, sino una forma puramente interior que puede (y de hecho debe) prescindir absolutamente de la individualidad de la contraparte. Es, en otros términos, una justicia sin relación intersubjetiva, fundamento práctico de una sociedad que no es ya comunidad ${ }^{18}$. La justicia se ha transformado en un problema exclusivamente político, y ya no es, por lo tanto, la virtud por excelencia de los ciudadanos.

Esta sistemática indiferencia teórica de la relación intersubjetiva concreta, explica la semejanza, esquiva pero no por eso menos clara, entre l'homme natural de Rousseau y el indi-

12 Cassirer, Ernst. "Kant e Rousseau”. En su: Rousseau, Kant e Goethe. Roma, Italia: Donzelli, 1999, p. 23.

13 Cfr. "Muthmaßlicher Anfang der Menschengeschichte" de 1786, obra traducida al español con diversos títulos. Sigo principalmente la traducción italiana KANT, Immanuel. Scritti politici. Torino, Italia: UTET, 1995, editada por editada por N. Bobbio, L. Firpo y V. Mathieu, y la traducción de Eugenio Ímaz (Comienzo presunto de la historia humana) en Kant, Immanuel. Filosofía de la Historia. D.F., México: Fondo de cultura Económica, 1992.

14 "What I have attempted to do is to generalize and carry to a higher order of abstraction the traditional theory of the social contract as represented by Locke, Rousseau and Kant”. Rawls, John. A theory of justice (revised edition). Oxford, Reino Unido: Oxford University Press, 1999, p. xviii

15 La referencia es, naturalmente, a Kant, Immanuel. "Dialéctica Trascendental” en su: Crítica de la razón pura. Madrid, España: Tecnos, 2002.

16 Cfr. el Corolario de Sobre el dicho común: Esto puede ser correcto en la teoría, pero no vale para la práctica (Über den Gemeinspruch: Das mag in der Theorie richtig sein, taugt aber nicht für die Praxis), II en su: Scritti politici, op. cit. (n.13). También se puede ver esta tesis en la parte relativa al "Derecho Público" en su: Metafisica dei Costumi. Milano, Italia: Bompiani, 2006 o bien La paz perpetua -6a edición-. Madrid, España: Tecnos, 1998.

17 Rawls, John. "Justice as Fairness: Political not Metaphysical", en: Philosophy and Public Affairs, Vol. 14, No. 3. (Summer, 1985), pp. 223-251.

18 Cfr. Guerrero, Juan A. "Vínculos y ciudadanía en la Teoría de la justicia de John Rawls". En: Villar, Alicia, et al. (ed.). Pensar la Solidaridad, Madrid, España: Ediciones de la Universidad de Comillas, 2004, quien, al comparar la difusa "amistad cívica” de Rawls con la "amistad política" de Aristóteles centra las diferencias precisamente en el hecho de que ésta última es "abstracta”. Por esta razón puede afirmar que "en realidad no es con personas como tales con quienes el individuo se vincula, sino con una colectividad indiferenciada, que no es exactamente lo mismo que muchas personas" (pp. 396-397). 
viduo bajo el velo de ignorancia de Rawls. En efecto, el salvaje de Rousseau es efectivamente capaz de ocuparse racionalmente de los otros, pero no por esto es capaz de amistad, benevolencia o siquiera de una verdadera relación interpersonal. En el estado de naturaleza, el "otro" se presenta primariamente al homme como medio o como obstáculo. Es cierto que la miseria del "otro" puede presentársele también como objeto de compasión; pero esta pitié, fundada por completo en el amour de soi, no constituye un acto de amor gratuito (imposible por hipótesis), sino un proceso de identificación empática mediante el cual el individuo, imaginándose en el lugar del otro, siente tristeza por su propia desgracia ${ }^{19}$. Así, si eventualmente hiciera algo por él, sería exclusivamente en virtud de una satisfacción propia, del amour de soi que es fundamento de toda bondad humana. La semejanza con el razonamiento de quien se encuentra tras el velo de ignorancia es evidente: el único motivo real para no consentir estructuras sociales "injustas" es que éstas podrían tocarme a mí, y este interés personal se transforma así en causa de la justicia de las instituciones. Volveremos sobre las consecuencias de esta tesis en el estado social; por ahora, baste adelantar que el panorama no será muy distinto, porque en realidad nada no puede haber en el citoyen que no estuviera antes prefigurado en el homme.

En síntesis, la hipótesis del estado de naturaleza o situación original como fundamento de la sociedad política presenta al menos dos graves problemas teóricos ${ }^{20}$.

El primero, más evidente, es el de la "cuadratura del círculo político"21: cómo fundar una sociedad de individuos asociales; cómo instaurar un gobierno político eficaz y que, sin embargo, los hombres sigan siendo libres ${ }^{22}$. De hecho, más allá de la coherencia de los diversos modelos y de efectiva praxis política que produzcan, todos los contractualistas, partiendo por el mismo Hobbes (quizás el mayor teórico de la "heteronomía" del derecho), proponen una idéntica legitimación abstracta de la ley: su reconducción lineal a la voluntad del individuo bajo

19 La teoría del amor de sí mismo, el amor propio y la compasión es tratada particularmente en el Discours sur l'origine et les fondements de l'inegalité parmi les hommes, PW, I, pp. 138, 160 y ss., 217; en el Émile, IV, pp. 491 ss. en su: Rousseau, Jean Jacques. Ouvres Complètes. Paris, Francia: Gallimard, 1959, edición a cargo de B. Gagnebin y M. Raymond, vol. IV; y en Rousseau juge de Jean-Jacques, Ibid., vol. I, Dialogue I, pp. 669-670; Dialogue II, pp. 805-806; 815; 861; 863-864.

20 Ninguno de los cuales tiene nada que ver con su a-historicidad, pues ningún contractualista sensato pretendió nunca que la tuviera. Al contrario, Rousseau es categórico al afirmar que se debe comenzar por "par écarter tous les faits; car ils ne touchent point à la question" (PW, I, p. 141). La misma idea en el Manuscrito de Ginebra, I, V, primera versión del Contrat Social (PW, I, p. 462).

21 La expresión es de Rousseau, de la Lettre a Cristophe de Beaumont, Archevêque de Paris (en su: Rousseau, Jean Jacques. Ouvres Complètes, op. cit. (n.19), vol. IV), interpretada según la lectura que propone Gentile, Francesco, "La cuadratura del 'círculo político", en su: en Inteligencia política y razón de Estado. Buenos Aires, Argentina: EDUCA, 2008, pp. 121-127.

22 El problema, típicamente aristotélico (Cfr. Aristóteles, Politica -3a edición-. Milano, Italia: Bur, 2008, III, 1277b 5-10), es íntegramente recogido por RousseAu, quien lo plantea como propósito fundamental de su obra: "Trouver une forme d'association qui défende et protége de toute la force commune la personne et les biens de chaque associé, et par laquelle chacun, s'unissant à tous, n’obéisse pourtant qu'à lui-même, et reste aussi libre qu'auparavant'. Tel est le problème fondamental dont le Contrat social donne la solution" (Contrat Social, I, VI, PW, II, p. 32). Quizás su enunciación más eficaz, que manifiesta abiertamente la paradoja implícita, es la del fragmento inédito 10 de la Lettre a Cristophe de Beaumont, Archevêque de Paris (Ouvres Complètes, op. cit. (n.19), vol. IV, p. 1019): "J'ai pénétre le secret des gouvernemens, je l'ai revelè aux peuples non pas afin quills scouassent le joug, ce qui ne leur est pas possible, mais afin quil redevinssent hommes dans leur esclavage (...) Quiconque ne reconnoit que les loix de la vertu et celles de la necessité n'est plus asservi aux hommes. Celui-là sait être libre et bon dans les fers". 
la forma de un consenso que es en realidad una renuncia. Con la permanente amenaza de terminar concluyendo con Rousseau que quien desobedece debe ser "forzado a ser libre" 23 , o con Orwell y el Gulag soviético, que el disidente político y el delincuente no requieren "pena”, sino "terapia" o "rehabilitación". La evidente ficción de esta identidad de voluntades fue malamente ocultada intentando hacer del Estado una "persona impersonal", una "persona anónima" que (continuando el oxímoron) se constituye como un "partisano divino" que, no reconociendo más ley que la suya, me somete sin que yo me someta a nadie de particular ${ }^{24}$. En último término, se trata siempre del eterno problema de distinguir realmente el derecho de la fuerza.

El segundo problema, más importante para nuestro propósito, es la imposibilidad de hacer filosofía política sin una antropología implícita. La cuestión, denunciada en su momento de modo incompleto y parcial por Carl Schmitt ${ }^{25}$, se hace manifiesta en las mismas tesis que intentan conjurarla. Así, por ejemplo, según Rawls el hombre en la situación original no es ni egoísta ni altruista, sino simplemente razonable, asumiendo de este modo una noción particularmente controvertible de la "razonabilidad"; del mismo modo, en esta situación los hombres ignoran sus propias concepciones sobre el bien, asumiendo por hipótesis, por lo tanto, que definirlas es materia de una elección libre. En el fondo, se trata simplemente de constatar que el debate entre cognitivismo y no cognitivismo éticos, antiguo como el Eutifrón, sólo se resuelve apelando a un determinado concepto de la naturaleza humana y de su puesto en el mundo. La del no-cognitivismo práctico es una antropología negativa, ciertamente, pero es antropología al fin, y una antropología extremadamente "comprehensiva".

\section{i.2. ANTropología Negativa Y NEUtralidad}

La cuestión queda más clara cuando se la traslada al ámbito rigurosamente político, porque entonces este prudente "escepticismo metafísico" sobre la naturaleza del hombre se transforma en "neutralidad" o "imparcialidad" política ${ }^{26}$. Esta idea ha sido profusamente criticada, sobre todo en ámbito comunitarista. Me aquí interesa una objeción en particular: la imparcialidad es autocontradictoria, porque no es imparcial. Al contrario, para decirlo en términos rawlsianos, la neutralidad es una "doctrina comprehensiva", quizás la más comprehensiva de todas, porque no excluye ninguna tesis. Este diagnóstico puede ser extendido a todas las versiones del formalismo, porque bajo esa "forma" (de lo político, de lo jurídico, de lo moral; no importa) cabe todo, siempre y cuando su contenido no contradiga la misma forma. En síntesis, la neutrali-

23 Contrat Social, I, VII, PW, II, p. 35: "quiconque refusera d'obéir à la volonté générale y sera contraint par tout le Corps: ce qui ne signifie autre chose sinon quion le forcera d'être libre".

24 Cfr. Gentile, Francesco. "El partisano divino", en su: Inteligencia política, op. cit. (n.21), pp. 69-76.

25 Cfr. todo el punto 7 de Schmitt, Carl. El concepto de lo politico. En: Aguilar, Héctor Orestes (ed.), Carl Schmitt, Teólogo de la política. D.F., México: Fondo de Cultura Económica, 2001, según el cual toda teoría genuinamente política debe partir del presupuesto de una antropología negativa, de un hombre "malo".

26 Conscientes de su eventual diferencia, desarrollada en una bibliografía inabarcable y de sentido escasamente unitario, tomaremos aquí los términos "imparcialidad" y "neutralidad" como sinónimos. 
dad valorativa no nos obliga a opinar nada en particular, pero nos obliga a opinarlo todo con una idéntica cláusula (valorativa) formal, que precisamente por ser formal, es omnicomprehensiva. En términos sencillos: piense usted lo que se le venga en gana, pero no pretenda que sea verdad ${ }^{27}$.

La cuestión puede ser ilustrada mediante un ejemplo: aquello que criticamos de las sociedades europeas durante las guerras de religión, lo que no logramos entender y nos parece la mayor expresión posible de su intolerancia, es que sus miembros, cuando se trataba de defender la fe, estaban dispuestos a "pagar cualquier precio, soportar cualquier carga, enfrentar cualquier dificultad, apoyar a cualquier amigo y enfrentar a cualquier enemigo". Según la tesis de Rawls, una postura de tal nivel de intolerancia excede toda racionalidad. El problema surge cuando constatamos que el autor de esta cita es John F. Kennedy en 1961, y no respecto a una fe religiosa, sino a "la supervivencia de la libertad". El suyo (y el de quienes incitaban a las guerras religiosas) es, en el fondo, el mismo razonamiento con el que el individualista Rousseau manda extirpar de la sociedad a todo aquel que se aparte de la religión civil ${ }^{28}$.

De modo rigurosamente análogo, este pretendido indiferentismo antropológico se transforma, a poco andar, en un completo sistema de antropología negativa. El grueso de la obra política y de teoría de la historia de Kant confirma esta tesis ${ }^{29}$. En la misma línea, leyendo la filosofía política desde Hobbes, Schmitt llega a afirmar que "la 'concepción pesimista' del hombre (...) hasta llegar por último directamente al bellum de todos contra todos, debe ser entendida no como parte de una fantasía medrosa y trastornada (...) sino como el presupuesto elemental de un sistema de pensamiento especificamente politico" 30 .

Así como un contrato entre individuos asociales es incapaz de fundar relaciones realmente jurídicas, distintas de las simples relaciones de fuerza, así también la neutralidad es estructuralmente incapaz de cumplir su principal promesa política: hacer posible el diálogo esencial a la deliberación pública. Su discurso, de hecho, es manifiestamente violento; tan violento como (mal que les pese) las instituciones de un Estado fundado en una revolución autojustificante ${ }^{31}$.

27 Parece ser este el trasfondo de la crítica de Robert George a la teoría de Rawls: el liberalismo político no es capaz de acoger en su seno las doctrinas comprehensivas con sus propias reglas, sino que les impone las suyas, deviniendo él mismo, inevitablemente, una doctrina comprehensiva. Cfr. George, Robert. "Democracia, ley y persona humana". En su: Moral Pública. Debates actuales. Santiago, Chile: Instituto de Estudios de la Sociedad, 2009, pp. 121-148 La paz perpetua, Respuesta a la pregunta: ;qué es ilustración? (Beantwortung der Frage: Was ist Aufklärung?); Idea de una historia universal en sentido cosmopolita (Idee zu einer allgemeinen Geschichte in weltbürgerlicher Absicht); Probable inicio de la historia (Muthmaßlicher Anfang der Menschengeschichte); El fin de todas las cosas (Das Ende aller Dinge) y Si el género humano progresa continuamente hacia lo mejor (Erneuerte Frage: Ob das menschliche Geschlecht im beständigen Fortschreiten zum Besseren sei). Hay traducción de algunas de ellas en Kant, Immanuel. Filosofia de la Historia, op. cit., e Ideas para una historia universal en clave cosmopolita y otros escritos sobre Filosofia de la Historia. Madrid, España: Tecnos, 1987.

31 Notables, es este orden, son las reflexiones del liberalísimo Kant sobre la justificación del hecho revolucionario a través de la simple efectividad del ordenamiento impuesto (cfr. Kant, Immanuel. Sobre el dicho común, op. cit. (n.16), II, corolario y Metafisica de las Costumbres, op. cit. (n.16) \$49 A, correspondiente a la sección primera de la parte II, referida al Derecho Público). 
Según propone Rawls en Liberalismo político, el ciudadano que participa del debate público debe evitar tomar partido a priori entre las diversas posiciones en juego y debe abstraerse de las propias: debe ser rigurosamente neutral. El primer problema, el más ingenuo, es que si todas las posiciones son equivalentes, ¿para qué sirve confrontarlas? Para hacer posible la convivencia, por supuesto. Pero esto supone reducir el debate público a un cálculo de intereses contrapuestos orientado a una transacción en la cual cada uno debe ceder (es decir, transigir en sus principios) sin otra razón que la fáctica oposición de fuerzas ${ }^{32}$. De hecho, cuáles sean los puntos particulares en los cuales cada doctrina comprehensiva deberá ceder o transigir dependerá exclusivamente de qué propongan en concreto las otras doctrinas efectivamente contrapuestas. Ante diversas contrapartes, diversas transacciones. Por otra parte, en este contexto las posiciones permisivas tendrán siempre todas las de ganar, con lo cual abandonamos la neutralidad antes de comenzar a aplicarla. Así, por ejemplo, si existe de hecho quien la defienda, ser neutral en el debate sobre la permisión legal del aborto significa siempre permitir el aborto, es decir, dejar de ser neutral ${ }^{33}$. Declararse neutral respecto a la verdad de toda tesis teórica significa declarar verdadera (y obligatoria) a una de ella en la práctica ${ }^{34}$.

En otros términos, el debate público no puede fundarse sobre la tesis de que todas las opiniones valen lo mismo, porque es evidentemente falsa; ni tampoco en la igual dignidad de todos los hombres, porque ésta es teóricamente inconducente y no permite concluir nada.

Como indica la más elemental experiencia, un debate genuinamente político y no simplemente ideológico, debe fundarse (y de hecho se funda) en el amor a la verdad y en el reconocimiento de la naturaleza del error. De hecho, todos los que participan honestamente en él, lo hacen en la medida en que consideran que tienen (al menos algo de) razón y, por lo mismo, son capaces de reconocer una condición semejante en sus interlocutores. El mal sólo subiste en el bien; el error sólo se puede proponer y comprender por lo que tiene de verdadero y de razonable. De este modo, el debate público no exige suponer que todas las posiciones valen, sino reconocer que todos, quien más quien menos, son inteligentes, y que por lo mismo, si se equivocan, es probablemente porque han visto una verdad que yo no. En cualquier caso, si diferimos es porque antes estamos de acuerdo en algo; de lo contrario, ni siquiera nos entenderíamos.

En síntesis, discutir con otro supone siempre al menos dos condiciones: a) creer que tengo razón y b) reconocer que el otro no es imbécil o perverso, y que por lo tanto, incluso estan-

La juridicidad del hecho revolucionario es, en efecto, la piedra de tropiezo de toda doctrina que no reconozca una juridicidad natural anterior y fundante del Estado.

32 En efecto, para Hobbes, "to convince a man is not to enjoy a common understanding with him, but to displace his reason by yours" (M. OAкеshotт, "Introduction”, en: Новbes, Thomas. Leviathan. Oxford: Blackwell, 1946, p. lvi)

33 Es ya un topos clásico, al respecto, la posición de Rawls sobre la permisión legal del aborto (Political Liberalism. New York, Estados Unidos: Columbia University Press, 2005, lecture VI, 7.2, nota, pp. 243-244), la cual se hizo más confusa cuando intentó aclararla (Ibid., p. liii-lv).

34 La paradoja de la neutralidad es el paralelo gnoseológico de la paradoja de la tolerancia. 
do equivocado, tiene algo importante que decir. No tendrá razón, pero ciertamente tiene razones. $\mathrm{Y}$ esas razones, si son tales, son comunicables. Lo diverso supone lo semejante. La cuestión es de capital importancia, porque si esto es verdad respecto de la neutralidad teórica, deberá serlo también respecto de la indiferencia antropológica y de la sociabilidad natural del hombre.

En efecto, en el orden político constitucional, la existencia de la sociedad supone dos condiciones perfectamente análogas a las ya indicadas: a) el reconocimiento una individualidad irreductible a toda otra, tanto en uno mismo como en los otros, la cual, sin embargo, b) se funda en una semejanza original que, en estricto rigor, no es otra cosa que la amistad natural entre los hombres. Será el tema de la segunda parte de este ensayo.

\section{I.3. ENTRE LA “insociable SOCIABILIDAD” y "LA POLÍtica COMO INCONVENIENTE"}

Con lo cual llegamos a un último punto crítico, quizás el fundamental: la tesis contractualista termina forzosamente por ver en todo hombre una amenaza para el individuo, y en el Estado y la política, un "inconveniente" provisoriamente necesario. En esta perspectiva, respecto de mis intereses particulares, por razonables que sean, el otro será siempre y sencillamente un medio o un obstáculo. Si es un medio, se lo utiliza; si es una amenaza, se lo destruye. Es la tesis del liberalismo ortodoxo y del capitalismo clásico. Piénsese, por ejemplo, en la reducción de la caridad y la generosidad a actos egoístas de autosatisfacción personal. El mismo Kant habla de una "benéfica discordia", efecto de la "insociable sociabilidad" que es causa de todo progreso humano ${ }^{35}$. Y en esta misma línea, las diversas ideologías de la modernidad, desde Hobbes a Locke, desde Saint-Simon a Marx, consideran la política y el Estado como un mal necesario, como una especie de prótesis moral que existe precisamente para poder dejar de usarla apenas la humanidad abandone su estado infantil. Algo que, de cualquier modo, es tiempo de superar definitivamente. La utopía típicamente moderna es la del fin de lo político ${ }^{36}$. Si la teoría rawlsiana carece de una "escatología" y se orienta simplemente a justificar un modelo político vigente es precisamente porque, de modo implícito, considera que lo genuinamente político ya ha muerto

35 "Entiendo en este caso por antagonismo la insociable sociabilidad de los hombres, es decir, su inclinación a formar sociedad que, sin embargo, va unida a una resistencia constante que amenaza perpetuamente con disolverla. Esta disposición reside, a las claras, en la naturaleza del hombre. El hombre tiene una inclinación a entrar en sociedad; porque en tal estado se siente más como hombre, es decir, que siente el desarrollo de sus disposiciones naturales. Pero también tiene una gran tendencia a aislarse; porque tropieza en si mismo con la cualidad insocial que le lleva a querer disponer de todo según le place y espera, naturalmente, encontrar resistencia por todas partes, por lo mismo que sabe hallarse propenso a prestársela a los demás. Pero esta resistencia es la que despierta todas las fuerzas del hombre y le lleva a enderezar su inclinación a la pereza y, movido por el ansia de honores, poder o bienes, trata de lograr una posición entre sus congéneres, que no puede soportar pero de los que tampoco puede prescindir" (KanT, Immanuel. Idea de una historia universal en sentido cosmopolita, IV principio, en su: Filosofía de la Historia, op. cit. (n.29), p. 46 ss.).

36 La tesis vale también, y quizás especialmente, para el liberalismo, al cual E. FAGUET pudo definir como la doctrina que niega la soberanía, elemento esencial al concepto moderno de política. Cfr. Dix-huitième siècle. Études littéraires. Paris, Francia: Société Française d'imprimerie et de librairie, 1890, p. 405: "L'idée libérale a été très lente à naître en Europe. Elle est essentiellement moderne; elle est d'hier. Elle consiste à croire qu'il n'y a pas de souveraineté; qu'il y a un aménagement social qui établit une autorité, laquelle n'est qu'une fonction sociale comme une autre, et qui, pour qu'elle ne soit qu'une fonction, doit être limitée, contrôlée, et divisée, toutes choses aussi difficiles, du reste, à réaliser, qu'elles sont nécessaires". 
absorbido en una técnica de cálculo para compatibilizar intereses contrapuestos. No puede haber verdadera política allí no hay nada realmente común entre los hombres, pues toda polis es una koinonia ${ }^{37}$.

La máxima elevación moral que cabe en este esquema es la indiferencia: no uso ni destruyo al otro, sino que reconozco su derecho a hacer lo que se le venga en gana y me prohíbo opinar. Es decir, lo ignoro. La sociedad de Rousseau es, en efecto, una comunidad de hombres profundamente incomunicados ${ }^{38}$, y es en ella que se inspira el kantiano reino de los fines ${ }^{39}$, sociedad perfecta de individuos absolutamente virtuosos y radicalmente incomunicados, antecedente directo de la sociedad equitativa propuesta por Rawls. Es este el espíritu que anima y posibilita la "coexistencia de los arbitrios" que define al concepto mismo de derecho.

Por otra parte, tratando todas las diferencias de modo igualmente indiferente, esta tesis, que ciertamente no es exclusiva del liberalismo, iguala todas las diferencias, abstrae al hombre real y termina por negar relevancia política a su individualidad. Todos son iguales ante aquel tercero ubicuo y anónimo que es el Estado; y en esta igualdad consiste la idea misma de justi$\mathrm{cia}^{40}$. Pero no es lo mismo tratar a todos por igual, que tratar a todos como iguales ${ }^{41}$. Así por ejemplo, es profundamente irrespetuoso igualar las creencias religiosas de una persona con la opción personal por un color de zapatos o el gusto de un tercero por disfrazarse de hipopótamo. El ejemplo es absurdo, pero manifiesta la urgencia de la pregunta de fondo, que no es ya "en virtud de qué principio tolerar lo diverso", sino "en virtud de qué principio diferenciar diferencias”. La respuesta a esta pregunta, si existe en absoluto, no puede ser hallada en el igualitarismo hipotético.

La cuestión que me interesa notar aquí es la radical insuficiencia del principio según el cual la sociedad justa es aquella en que a cada individuo sencillamente "se lo deja en paz" 42 con sus preferencias. La indiferencia no es un principio político viable. La polis es koinonía de hom-

37 Aristóteles, Política, op. cit. (n.22), I, 1252a 1; se trata de la primera línea de esta obra. Como es usual en el corpus aristotélico, esta primera frase enuncia buena parte del tema del resto del libro.

38 Cfr. Polin, Raymond. La politique de la solitude. Essai sur la Philosophie politique de Jean-Jacques Rousseau. París: Sirey, 1971, el cual se inicia con esta afirmación: "Si paradoxal que cela puisse paraitre, en affirmant, à travers la perfection solitaire de la divinité, la solitude fondamentale de l'homme, Rousseau a fourni le principe d'interprétation décisif de sa politique” (p. 1).

39 Para un estudio sobre la cuestión, vid. Rigobello, Armando (ed.). Il "Regno dei fini". Napoli, Italia: Istituto italiano per gli studi filosofici, 1996.. Vid. también Pirni, Alberto. "La Fondazione della Metafisica dei Costumi e il Regno dei fini: problema normativo e problema religioso in Kant". En: AA.VV. La trasmissione della filosofia nella forma storica. Atti del 33. Congresso nazionale della Società filosofica italiana, Genova, 30 aprile-3 maggio 1998, vol. 2: Comunicazioni e documenti. Milano, Italia: Franco Angeli, 1999, pp. 139-147, p. 142.

40 Nuevamente, esta idea típicamente rawlsiana tiene su origen en una de las ideas nucleares de la doctrina de Rousseau: la justicia y la libertad consisten total y exclusivamente en la igualdad.

41 Según la famosa distinción de Dworkin, Ronald. Taking Rights Seriously. Cambridge (MA), Estados Unidos: Harvard University Press, 1978, p. 227.

42 Significativamente, la expresión inglesa para esta situación es "to be left alone", como nota Gentile, Francesco. Inteligencia politica, op. cit. (n.21), p. 14. 
bres naturalmente sociales que viven unidos por una tradición, y contrariamente a lo que piensa Bobbio $^{43}$, esta tesis no constituye una nueva hipótesis análoga a la del estado de naturaleza, sino que pretende ser reconocida como un hecho de experiencia. Por lo mismo, si no es verdadera, deberá ser confutada desde la experiencia, no desde una nueva hipótesis.

Experiencia que, de hecho, parecería confutarla de modo abierto y manifiesto. Pocos hechos hay, en efecto, más evidentes a la experiencia que la discordia entre los hombres. Pero siendo la dis-cordia un fenómeno esencialmente negativo, que se define por su oposición a otra cosa (la con-cordia), la cuestión de fondo no será tanto la constatación de su existencia, sino el origen empírico de la concordia y amistad a las cuales se opone. Lo cual significa que esta concordia es forzosamente anterior.

En otro términos: la misma discordia, por ser negativa, supone y exige una concordia real a la cual oponerse. Sólo puede haber discordia entre aquellos que están relacionados de algún modo, y toda relación se funda en algo que es común: los discordes difieren porque previamente están de acuerdo. El disenso supone el acuerdo exactamente del mismo modo en que lo diverso supone lo semejante y se funda sobre ello. No hay disenso posible entre dos personas que no se han comunicado, y para hacerlo, es necesario que se reconozcan como semejantes y compartan algo que les permita hacerse entender.

Como bien vio Rousseau, si la discordia es realmente natural o inevitable, no será posible solucionarla mediante aquel tertium quid hobbesiano que, sobreponiéndose a todos por igual, neutraliza a las partes en conflicto. Ante este "nudo político" constituido por el conflicto entre los hombres hay sólo tres alternativas: cortar el nudo, ignorando sistemáticamente todo vínculo jurídico real entre los hombres a través de la superposición de un Estado omnipresente, como propuso Hobbes; negarlo, intentando fundar una sociedad al margen de toda relación, como quiso hacer Rousseau, o bien, por último, intentar desatarlo, para lo cual el primer paso es conocerlo ${ }^{44}$, identificando lo común y lo diverso en cada uno de sus extremos ${ }^{45}$.

43 Воввго, Norberto. "Il modello giusnaturalistico", En: Rivista internazionale di filosofia del diritto, L (1973), pp.603-622, republicado en Воввіо, Norberto. Thomas Hobbes. Torino, Italia: Einaudi, 1989, pp. 3-26.

44 Aristóteles, Metafísica III, 995a 30. Utilizo la edición de Reale, Giovanni. Introduzione, traduzione e commentario della Metafisica di Aristotele. Milano, Italia: Bompiani, 2004.

45 Es la definición platónica de dialéctica, tal como aparece en Platón, Politico, 285 A-B (Parménides; Teeteto; Sofista; Político. Madrid, España: Gredos, 1992). Dialéctica que, de hecho, se constituye como opuesto especular de la ciencia hipotéticodeductiva. 


\section{LA AMISTAD POLÍTICA: PRINCIPIO CONSTITUCIONAL}

\section{I. LA LEY Y LA VIRTUD}

La filosofía clásica ${ }^{46}$ supone en primer lugar un cambio de perspectiva. En primer lugar, su objetivo no es la certeza de una ciencia hipotético-deductiva, sino la verdad de la experiencia, aunque el grado de certeza sea menor. Esta ciencia no se define por el método, sino por su objeto; en efecto, su regla metodológica fundamental es que no se puede aspirar al mismo rigor y exactitud en todos los ámbitos del saber ${ }^{47}$. En este contexto, por la naturaleza misma de su objeto (que es particular y contingente) la filosofía práctica es esencialmente dialéctica y por consiguiente también lo es el Derecho. El saber del jurista es una "verdadera y no fingida filosofía" 48.

Según la tesis clásica, pre-moderna, el fin de la ley es "hacer buenos a los hombres" ${ }^{49}$, porque no es posible que hombres malos actúen constantemente bien. El hecho de que esta virtud de los ciudadanos sea buscada sólo en cuanto afecta a otros en nada obsta al punto central: el bien de la comunidad exige que los ciudadanos sean buenos y justos, al menos en una medida mínima. Es decir, los clásicos sabían muy bien que "no se puede mandar todo lo bueno ni prohibir todo lo malo" 50 , sino solamente aquello que sea socialmente relevante. Y esto no solamente por prudencia, porque se causarían muchos males, sino directamente porque es imposible. La ley no puede actuar inmediatamente sobre la conciencia de los ciudadanos; no es que no deba, sino que no puede. Como demuestra la historia (y ya advertía San Agustín) una ley de este tipo no podrá lograr más que una confesión hipócrita. Pero eso no significa que la ley no actúe de ningún modo sobre las conciencias; de hecho, su efecto propio es obligar, lo cual no es otra cosa que vincular conciencias a un bien debido.

La ley hace buenos a los hombres de dos modos: $1^{\circ}$ impidiendo que sean gravemente malos (la vis coactiva) y $2^{\circ}$ presentándoles determinados bienes sociales para que los amen libremente, para que sean buenos desde sí mismos (la vis directiva) ${ }^{51}$. Lo cual supone que ya son previamente buenos y virtuosos en una cierta medida. En efecto, la misma vis coactiva sólo es efectivamente disuasiva en la medida en que apele a bienes que, si bien el individuo percibe en

46 Entiendo con este término la tradición filosófica que, iniciada con Platón, se extiende hasta la segunda escolástica española, caracterizada fundamentalmente por el realismo filosófico, la apertura a la experiencia y la dialecticidad del conocimiento práctico.

47 Cfr., por ejemplo, Aristóteles, Etica Nicomaquea, op. cit. (n.1), I, 1094b 25-27.

48 Cfr. el Digesto I, 1, 1: "iuri operam daturum prius nosse oportet, unde nomen iuris descendat. Est autem a iustitia appellatum: nam, ut eleganter Celsus definit, ius est ars boni et aequi, cuius merito quis nos sacerdotes appellet: iustitiam namque colimus et boni et aequi notitiam profitemur, aequum ab iniquo separantes, dicitum ab illicito discernentes, bonos non solum metu poenarum, verum etiam praemiorum quoque exortatione efficere cupientes, veram nisi fallor philosophiam, non simulatam affectantes".

49 Tomás De Aquino, Summa Theologiae, I-II, q.92, a.1 (Se utiliza la siguiente edición: Suma Teológica. Madrid, Espańa: Biblioteca de Autores Cristianos, 1954-1957; en adelante, se citará simplemente como S. Th., seguido de la parte y el artículo en cuestión).

50 Esta es, por ejemplo, la tesis recogida por TomÁs de Aquino, S. Th., I-II, q. 96, a.2-3.

51 Tomás de Aquino, S. Th., I-II, q.96, a.5. La distinción explícita entre vis coactiva y vis directiva de la ley se encuentra en la respuesta a la tercera objeción. 
primer lugar como privados, siguen siendo esencialmente comunes, y por lo tanto pueden ser materia de ley. El malo puede ser convencido de hacer el bien porque en realidad no odia lo bueno, sino que lo desea de modo parcial e imperfecto: en cuanto le conviene.

El punto fundamental es que toda ley, si es verdaderamente ley, se dirige a hombres, y por lo tanto actúa sobre la razón, que es forma de la virtud moral; de lo contrario, será pura fuerza dirigida a autómatas, a los cuales tratará como cosas. Quinientos ańos de voluntarismo teórico demuestran que si la ley es puro acto de una voluntad superior, no hay modo de distinguirla de la fuerza.

Este ordo rationis que busca instaurar la ley es idéntico al ordo virtutis que hace bueno a todo el hombre; en otros términos, la virtud no es otra cosa que la concreción singular de la recta ratio manifestada en términos universales por la ley. Análogamente, la vis coactiva es la forma menos perfecta de la vis directiva, porque el primer requisito para ser bueno y virtuoso es no ser malo.

\subsection{UNA NUEVA (O VIEJA) ANTROPOlogía: DE LA AMISTAD NATURAL A LA NATURALIDAD DE LA POLIS}

Lo que subyace a esta diferencia en el modo de entender la ley, sin embargo, es mucho más profundo que su mero concepto: es un diverso concepto de hombre y, por lo mismo, un diverso concepto de la naturaleza del vínculo político.

Si la ley hace virtuosos a los hombres, es porque éstos ya lo son (al menos en parte) por sí mismos. De la misma manera, el fin de la sociedad política es que los hombres sean amigos, precisamente porque ya son amigos al momento mismo de unirse en sociedad. "The stability of a polis depends on the enduring sentiment of friendship between good men"52. La cuestion es fundamental, porque, evidentemente, no será igual una constitución pensada para una sociedad de demonios (la palabras son de $\mathrm{Kant}^{53}$ ) que una que fundada sobre la amistad natural entre los hombres.

La tesis de esta segunda parte es que, tal como afirma la tradición platónica y aristotélica, la sociabilidad del hombre no es otra cosa que una amistad natural del ciudadano por sus semejantes y, por lo tanto, el fundamento de la sociedad política y "causa eficiente" 54 del Estado es la concordia política, forma mínima de la amistad electiva.

El objeto del amor es el bien, y el primer bien de cada cosa es su propia subsistencia. Por esta razón, es natural en el hombre el amor a aquello que percibe como más próximo o semejante a sí mismo. "Lo semejante, hablando propiamente, es naturalmente deseable y amable; por ac-

\footnotetext{
52 Voegelin, Eric. Order an History. En su: The Collected Works of Eric Voegelin. Columbia: University of Missouri Press, 2000, vol. 16, p. 375, leyendo a Aristóteles. Son pocos los autores que han notado como Voegelin la centralidad del problema de la homonoia y de la philia politike aristotélicas.

53 Kant, Immanuel. La paz perpetua, op. cit. (n.16), p. 37.

54 Analógicamente, pues sólo la sustancia tiene causa.
} 
cidente, se desea lo contrario, en cuanto es útil o medicinal' 55 . De lo cual se sigue una interesante conclusión: no es necesario tener motivos especiales para amar, porque basta la mera semejanza; sí son necesarios, en cambio, motivos para odiar ${ }^{56}$. El amor es anterior a la discordia.

Esta semejanza es causa del amor más natural: el de la familia, la cual es, simultáneamente, lo más próximo y lo más semejante a nosotros mismos. Por eso, según un principio que se ha hecho cliché, la familia es la base de la sociedad. Esto no es verdadero solamente en el orden material (la sociedad está hecha de familias, no de individuos) sino sobre todo en el orden formal: las relaciones familiares son el modelo primario a partir del cual concebimos toda otra relación social, partiendo por aquellas de comunidad, autoridad o igualdad. Dentro de estas relaciones, la primera y fundamental, de la cual surge toda otra, es aquella que se funda en la amistad más natural: la mutua inclinación del hombre hacia la mujer y viceversa. "El hombre es más un animal conyugal que politico" 57.

De modo análogo, existe una natural benevolencia respecto de todo hombre, la cual se acentúa en la medida de su proximidad o semejanza con la propia experiencia y el propio mundo. Benevolencia que, por cierto, puede ser ineficaz en la vida cotidiana, pero que no por eso es menos real, pues no es esencial al afecto el traducirse en conductas concretas. En su dimensión política, esta inclinación constituye el amor natural de todo hombre por sus conciudadanos. Ciertamente esta inclinación no es suficiente para constituir una sociedad. Por ahora, sin embargo, basta constatar que, cumpliendo con las condiciones identificadas por Aristóteles (referido a otro, mutuo y público ${ }^{58}$ ), este amor natural puede ser considerado "amistad". Las cosas reciben su nombre por lo mejor que hay en ellas y por su semejanza con lo perfecto y acabado. Lo mismo podremos decir, entonces, respecto de aquella "amistad en virtud de lo útil" que constituye el primer vínculo social.

La tesis de Aristóteles respecto de la sociedad política es el contrario de su afirmación citada al inicio: amigos, si hay amigos; por eso hay sociedad. Y si bien se puede razonar políticamente como si no existiera esta amistad, en nada obsta la plausibilidad de semejantes teorías al hecho concreto de que si hay sociedad es porque los hombres son amigos. Ubi societas, ibi amicitia, y es precisamente gracias a la concretísima existencia de esta amistad natural con sus pares conciudadanos que el filósofo escéptico puede abstraerse de ella en la intimidad de sus estudios para negar sistemáticamente su existencia. Pero (como demuestra la biografía de Hobbes y tantos otros) apenas esos amigos dejen de existir efectivamente, tendrá que abandonar toda teorización abstracta y simplemente huir.

\footnotetext{
55 Tomás de Aquino, Comentario a la Ética a Nicómaco. Pamplona, España: Eunsa, 2000, VIII, 1, n.1087, p. 312.

56 Es notable el hecho de que, en Kant, Immanuel. La paz perpetua, op. cit. y en otros textos análogos, Kant sostiene una tesis exactamente opuesta: la guerra no necesita de motivos particulares porque es connatural al hombre.

57 Tomás de Aquino, Comentario a la Ética a Nicómaco, op. cit. (n.55), VIII, 12, n.1233, p. 342

58 Cfr. Aristóteles, Ética Nicomaquea, op. cit. (n.1), VIII, passim.
} 
Pese a su enorme fuerza emotiva, el ideal revolucionario de la fraternidad ha sido ampliamente ignorado por la teoría política moderna, y los intentos de rehabilitarlo han sido siempre estériles. Posiblemente, la razón es que este ideal es contrario a las premisas del sistema revolucionario que lo propuso en primer lugar, sistema cuyo propósito es precisamente unir a hombres que se odian por naturaleza.

\subsection{LA AMISTAD COMO FIN Y COMO PRINCIPIO}

Al margen de toda abstracción, lo cierto es que no se puede fundar una sociedad concreta en la discordia, en la lucha entre sus partes o en la competencia. Ya Platón sabía que "toda ciudad dividida no subsistira" 59 . Aristóteles, por su parte, propone la misma tesis en una cita bellísima, que nunca será suficientemente estudiada:

"La amistad, según parece, mantiene unida las ciudades, y los legisladores se ocupan más de la amistad que de la justicia; en efecto, se dice que la concordia es semejante a la amistad, y los legisladores buscan sobre todo aquella"60.

En otros términos: la amistad no es sólo fin. También lo es, y la cuestión ha sido profusamente argumentada por la doctrina social de la Iglesia ${ }^{61}$. De hecho, allí donde reina la amistad, la justicia se da por descontada y la ley es prácticamente innecesaria. En este sentido, la amistad no sólo es garantía del bien común, sino que ella misma es un bien común que debe ser buscado y fomentado. Estos ideales de "bien común" y de "amistad" son ya bastante diversos de la mera coexistencia pacífica de los individuos propuesta por Kant o Rawls. Sin embargo, me parece que la originalidad de la tesis aristotélica se encuentra sobre todo en otro punto.

La amistad es también principio, no sólo ideal o propósito. En efecto, en el orden práctico finis est principium ${ }^{62}$. La concordia política u homonoia es como la causa eficiente de la sociedad política, porque es el vínculo político natural: es aquello que une concretamente a los hombres en sociedad ${ }^{63}$. Y esta concordia, siempre según Aristóteles, es una forma de $\operatorname{amistad}^{64}$.

\footnotetext{
Mt. 12, 25.

60 Aristóteles, Ética Nicomaquea, op. cit. (n.1), VIII, 1155a 20-30.

61 Es también tesis de Tomás de Aquino: el fin de la ley humana es que los hombres sean amigos. Cfr. S.Th., I-II, q.99, a.1, ad 2; a.2.

62 El principio, aristotélico en su origen, es profusamente utilizado por ToMÁs DE AQuino. Cfr., por ejemplo, entre tantos otros, S. Th., I-II, q. 57 a.1; II-II, q.23 a.7 ad 2; II-II, q.47, a.6.

63 Lamas, Félix Adolfo. La concordia politica. Buenos Aires, Argentina: Abeledo-Perrot, 1975. Una síntesis de sus tesis, enriquecidas con ulteriores desarrollos teóricos, se puede encontrar en el artículo para uso de sus alumnos en LAMAs, Félix Adolfo. < En línea> "La concordia política" [citado 15 de octubre de 2011]. Disponible en la World Wide Web: <http://www.viadialectica. com/fil_estado.html>

64 Cfr. Aristóteles, Ética Nicomaquea, op. cit. (n.1), VIII, 1155a 24-25; IX, 1167a 21 - 1167b 15, en especial 1167b 1-4; ArIsTÓTELEs, Ética Eudemia. En su: Le tre etiche, op. cit., VII, 1241a - 1241b 10.
} 
Evidentemente, no se trata aquí de la amistad de dos personas que se aman y que son, al decir de Agustín, "un alma en dos cuerpos" ${ }^{5}$. Se trata de la forma más básica de amistad, la amistad útilib, aquella en que cada uno quiere el bien del otro como propio en cuanto condición del propio bien. Este tipo de amor supone un acuerdo fundamental respecto de los fines y, sobre todo, respecto de lo que hay que hacer para obtener aquello que ambos queremos ${ }^{67}$.

El ejemplo más evidente es el de una sociedad comercial, en la cual los fines subjetivos de cada socio son indiferentes siempre y cuando no se opongan, sino que colaboren al bien de ambos. O, más claro, un equipo de fútbol: el fin del arquero o del delantero es idéntico al fin de la sociedad que componen: ganar el partido. Para lograrlo, deben ejecutar acciones que, en sí mismas, están orientadas a este fin, aun cuando es perfectamente posible que ese único fin sea querido de modo oblicuo o indirecto, como el delantero que juega para lucirse. Estos fines subjetivos, si bien son menos nobles, son perfectamente lícitos y útiles mientras no se opongan al fin del todo, como en el caso del jugador que no la pasa a nadie para lucirse sólo él. Pero el punto está precisamente allí: en la medida en que su fin personal difiera del fin del todo, en esa misma medida dejará de obtenerse el fin del todo, y por lo tanto también su propio fin.

El error del liberalismo es creer que los fines individuales son los únicos fines posibles, y que los bienes sociales se producen como por arte de magia a partir del puro interés individual; el error opuesto, no menos grave, es creer que sólo son lícitos los fines sociales directamente queridos, y que los fines individuales son siempre deleznables porque pervierten necesariamente la acción. El elemento común a ambos errores es que, en ambos casos, el hombre es naturalmente malo y egoísta y debe ser "corregido" por el Estado.

Los ejemplos propuestos permiten notar dos aspectos fundamentales de la concordia que contradicen empíricamente este presupuesto del homo lupus.

Primero, la concordia política es un acuerdo objetivo, y precisamente por eso es también un acuerdo natural, anterior a toda elección. Los concordes no acuerdan ponerse de acuerdo ${ }^{68}$, sino que se encuentran de acuerdo, y sólo deben acordar cómo obtener eso en lo cual ya están

65 Agustín, Confesiones, IV, 6, 11. Se utiliza la siguiente edición: Agustín. Confesiones. Madrid, España: Biblioteca de Autores Cristianos, 2005.

66 Es cierto que, como reconoce Aristóteles y comenta Santo Tomás, la amistad útil, junto a la amistad por lo deleitable, constituye la forma más frágil de amistad, porque se acaba apenas termina el deleite o la utilidad que la causa. Pero se trata aquí de ciertos bienes fundamentales que nunca dejan de ser necesarios, es decir, de algo que es "útil durante toda la vida" (TomÁs DE Aquino, Comentario a la Ética a Nicómaco, op. cit. (n.55), VIII, n.1189, p. 333).

67 Que se trata efectivamente de una forma de amistad, si bien la menor de todas, queda claro cuando se consideran los efectos de ésta: benevolencia (querer el bien del otro), beneficencia (ejecutar actos que producen un bien al otro) y concordia (convivir, elegir lo mismo y gozar o dolerse de lo mismo). De estos tres, el más necesario y menos perfecto es la concordia, de donde toma su nombre la amistad política (cfr. Ibid, n.1292-1295, pp. 356-357). En otros términos, la amistad no es lo mismo que la concordia, que es sólo el menor de sus efectos; pero tratándose también de la forma mínima de la amistad (la útil), resulta que la amistad política es lo mismo que la concordia política (Ibid., n.1323, p. 364).

68 Cfr. Lamas, Félix Adolfo. La concordia politica, op. cit. (n.63), p. 209. 
de acuerdo. Que un acuerdo sea objetivo significa simplemente que los diversos individuos se encuentran a sí mismos queriendo lo mismo que los demás, y en virtud de esa coincidencia de voluntades, se unen. En el caso de la vida social, la materia del acuerdo es simplemente la conveniencia de no vivir solos y una valoración positiva del esquema de bienes sociales en el cual se fue educado, el cual, por fuerza, será el criterio para calificar cualquier otro esquema de bienes o incluso para reprobar el propio ${ }^{69}$. Todo hombre, de modo espontáneo y natural, percibe como un bien la tradición en que fue formado, incluso cuando, en su adultez, la critique o repruebe.

La materia del acuerdo no es unirse, sino el modo de obtener los fines que nos unen. La concordia es causa de la sociedad, pero no es cronológicamente anterior a ella. Sólo la reducción nominalista de la voluntad a un acto monádico y aislado ${ }^{70}$ obligó a identificar la volición constante de los fines con un acto de elección, confundiendo así la concordia de las voluntades con un acto expreso de suscripción de un contrato. Es esta la premisa básica de todas las formas de contractualismo.

Decir que la unión política es producida por la voluntad no significa decir que ésta consiste en una elección, a menos que se pretenda afirmar que no existe más acto voluntario que la elección. E incluso si fuera la sociedad fuera efectivamente el producto de una elección libre, de un contrato, esta misma elección supondría un acuerdo objetivo anterior: el acuerdo sobre la necesidad de abandonar el estado de naturaleza. La cuestión fundamental es notar que toda unión supone una comunidad previa; a la inversa, no es posible unir dos cosas que no tienen nada en común.

En segundo lugar, la concordia es un acuerdo de voluntades, no de opiniones ${ }^{71}$. Los socios se unen porque quieren lo mismo, y las razones por las que lo quieren o los aspectos bajo los cuales lo quieren resultan secundarios, como se aprecia claramente en los ejemplos propuestos. La semejanza que funda la amistad respecto de lo útil no tiene por qué ser semejanza entre los

69 Toda crítica de la propia tradición es siempre una crítica interna, porque no puede ser sino ella misma la que aporte los principios y elementos conceptuales para criticarla. Todo movimiento, por violento o autodestructivo que sea, comienza en el punto en el que se está.

70 Cfr. T. Hoвbes, EW, IV, Elements of Law, natural and civil, p. 69, donde se afirma que las voliciones "proceed not from, but are the will; and the will is not voluntary: for a man can no more say he will will, than he will will will, and so make an infinite repetition of the word; which is absurd, and insignificant". Por ets misma razón, según Rousseau, "Chaque acte de souveraineté, ainsi que chaque instant de sa durée, est absolu, indépendant de celui qui précède; et jamais le souverain n'agit parce qu'il a voulu, mais parce qu'il veut". Extremadamente sugestiva la tesis de Lucien JaumE, a quien le parece encontrar un "sorprendente paralelismo" con "el instantaneismo" del cogito cartesiano de las Meditaciones Metafísicas (cfr. "Rousseau e la questione della sovranità". En: Duso. Giuseppe (ed.). Il potere. Per la storia della filosofia politica moderna. Roma, Italia: Carocci, 1999, p. 186, nota 31: "Non soltanto la volontà generale non può impegnare l'avvenire (se si considerano le leggi votate) ma non può impegnare se stessa per l'avvenire: è un nunc stans, un "Io voglio" sempre da rinnovare in una serie d'atti di presenza a sé, i quali costituiscono la vivente volontà generale”).

71 Tomás De Aquino, S. Th., II-II, q.37, a.1. Cfr. In II Sententiarum, d.11, q.2, a.5 ad 1; d.27, q.2, a.1; In IV Sent, d.13, q.2, a.3 ad 1 (consultado en la siguiente edición: Comentario a las Sentencias de Pedro Lombardo. Pamplona, España: Eunsa, 20022008); S. Th., II-II, q. 29, a.1 ad 2. Vid. Schwartz Porzecanski, Daniel. "Aquinas on Concord. 'Concord Is a Union of Wills, Not of Opinions", en: The Review of Metaphysics, Vol.57, No.1 (2003), pp. 25-42. 
mismos sujetos que se unen. De hecho, personas profundamente diversas pueden querer lo mismo por las razones más variadas. Así, lejos de oponerse a la diversidad social, la concordia es la semejanza mínima que la hace posible.

Así, la amistad resulta ser entelequia ${ }^{72}$ de la sociedad política: simultáneamente forma y fin. Punto de partida y perfección de una misma cosa. Aquello a lo que se tiende porque es aquello de lo cual se parte. Entre medio, se ubica toda la inagotable trama de opciones, intereses y opiniones que fundan todos los acuerdos y desacuerdos que constituyen las sociedades concretas.

No parece haber otro principio capaz de dar cuenta de la experiencia política y jurídica cotidiana. Por lo general, la gente respeta espontáneamente las leyes fundamentales, obedece a las autoridades incluso si las considera ineptas, reconoce la legitimidad de las leyes que reprueba y, sobre todo, se relaciona pacíficamente con sus semejantes. Nada de esto puede ser explicado por mero cálculo de intereses, deberes contractuales o miedo a la sanción. Es un simple prejuicio moderno, que no resiste análisis, el explicar la vigencia del derecho por la coacción. La causa de una acción virtuosa no puede ser sino la virtud, y el motor de la virtud es simplemente el amor del bien. Los hombres son buenos y justos porque son amigos; y es sólo esta bondad y justicia la que hace posible la vida social. Los (evidentes) límites de esta justicia son los límites de esta virtud; y a cada régimen político corresponde una forma de justicia, pero también una forma de amistad $^{73}$.

La cuestión es demostrable también por vía contrafáctica: la ausencia total de amistad es la definición de la tiranía, porque la tiranía es aquel régimen en el cual entre los fines del tirano y los fines de su pueblo no hay nada común, y por lo tanto, el tirano usa del pueblo como si fuera un instrumento, es decir, ni siquiera lo reconoce como un igual ${ }^{74}$.

La misma justicia, que es fin de la politeia, es principio de amistad. Como afirma Aristóteles, la amistad es más que la justicia, y por lo tanto la implica ${ }^{75}$. Y a la inversa, la misma a igualdad lo desigual" y esta igualdad "es lo último en la justicia, y lo primero en la amistad"76. Entre amigos no hay disensión porque lo propio de la justicia se cumple espontáneamente, y si falla la regla de justicia es porque se da más, no menos de lo debido.

72 El término aristotélico plantea serios problemas críticos. Para nuestro propósito, no obstante, basta constatar que su significado reúne al menos tres elementos fundamentales: la entelequia es forma (es decir, lo que da el ser tal), es fin (es decir, plenitud y perfección de la forma) y es acto (es decir, determinación real). Para una introducción breve, actualizada y profunda, cfr. BERTI, Enrico et al. Voz "entelechia". En: Enciclopedia filosofica. Milano, Italia: Bompiani, 2006, pp. 3420-3423.

73 Aristóteles, Ética Nicomaquea, op. cit. (n.1), VIII, 1141a 10.

74 La idea atraviesa la Platón, República, op. cit. (n.1) (en particular VIII, 562a -IX, 576b) y la Aristóteles, Política, op. cit. (n.22), en particular IV, 1295a y V, 1310b hasta el final. Para la idea del uso instrumental del pueblo, cfr., por ejemplo, TomÁs De Aquino, Comentario a la Ética a Nicómaco, op. cit. (n.55), VIII, n.1212-1213, p. 338.

75 Cfr. Aristóteles, Ética Nicomaquea, op. cit. (n.1) VIII, 1155a 25-30; 1159b 25-30; Aristóteles, Ética Eudemia, op. cit. (n.64), VII, 1234b.

76 Tomás de Aquino, Comentario a la Ética a Nicómaco, op. cit. (n.55), VIII, n.1158, p. 328. 
Por otra parte, la misma justicia exige una comunidad inicial, un bien que vincule a ambas partes y los mueva a establecer la relación. Un bien común. Es esta la razón de la insuficiencia de la justicia conmutativa (que es, precisamente, justicia particular) para explicar la vida social. La pura justicia conmutativa, sin referencia alguna a lo que es común a todos (es decir, abstraída de la justicia general), exige simplemente que se le dé al otro lo que es suyo: todo lo suyo y nada más ${ }^{77}$.

Lo que hoy solemos llamar "solidaridad" no es otra cosa que la clásica justicia general bien correctamente entendida y completamente aplicada: la primacía del bien común sobre el bien particular.

\subsection{Dos objeciones: multiculturalismo y utopía}

Al menos dos objeciones suelen levantarse contra las tesis aquí enunciadas, y ambas se reducen a una misma: su aparente ingenuidad y candidez ${ }^{78}$. Pareciera ser que, junto con Carl Schmitt, el sentido común contemporáneo identifica linealmente el realismo con el pesimismo escéptico.

La primera de estas objeciones es una acusación general de utopismo: todo esto suena muy bien, pero es sencillamente imposible, y las consecuencias prácticas de intentar aplicarlo serían catastróficas.

La segunda es relativa al problema del multiculturalismo, el cual parecería contradecir en vía puramente empírica las tesis aquí expuestas, reduciéndolas a meras especulaciones románticas. En efecto, no parecería posible siquiera proponer el tema de la amistad política en una sociedad en la cual coexisten culturas y visiones del mundo profundamente diversas y, no pocas veces, enfrentadas. Lo desemejante, decía el mismo Aristóteles, no produce amistad.

Corolario de estas acusaciones es que, al parecer, se estarían ignorando siglos de filosofía política; más específicamente, los siglos de la modernidad. Al respecto, me limito a constatar, como ya demostraron (con todas sus diferencias) Leo Strauss, Hannah Arendt o Eric Voegelin y anunciaron unánimes los mismos autores modernos al plantear estas tesis, que existen ciertos elementos característicos y unificantes de la filosofía jurídica moderna, los cuales implican un modo totalmente diverso de concebir la vida política.

Una de las diferencias más notorias entre estos dos modos de concebir la polis, que sirve clásica no es en primer lugar conocimiento práctico, sino teórico ${ }^{79}$; su fin no consiste en cons-

El que no llama a Carabineros cuando nota que alguien asalta a su vecino o el que se alegra interiormente de la desgracia del prójimo y toma palco para contemplarla, no actúa con injusticia.

78 Agradezco a Juan Pablo Mañalich por hacerme notar (a su modo) este punto.

79 Muy interesantes y atingentes a este problema resultan las observaciones de Widow, Juan Antonio. "La universalidad de la norma y la filosofía práctica”, en: Revista Internacional de Filosofía Práctica (Instituto de Estudios Filosóficos Santo Tomás de 
truir la polis perfecta, sino en entenderla tal como es. El núcleo de la cuestión es que, como afirma Aristóteles y confirma Hobbes, si no hay mayor bien para el hombre que el mismo hombre (principio coesencial a un "estado de naturaleza"), la primera de las ciencias será forzosamente una "philosophia civilis" entendida como el conocimiento necesario para conformar el Estado ${ }^{80}$. El punto de partida de la filosofía política clásica era especularmente inverso: el hombre no es todo el bien.

De este modo, la respuesta a las objeciones radica en que, si las tesis expuestas son correctas, la amistad política no es un ideal al cual sea necesario u obligatorio aspirar, sino un dato de la causa; quizás el primer dato de la vida social: la sociedad es una comunidad ${ }^{81}$. Si estas tesis son verdaderas, la misma sociedad existe en la medida en que realiza de modo parcial y dinámico, y por lo tanto imperfecto y siempre inacabado, el principio de la amistad política. Amistad que, según decíamos, es en primer lugar principio, y por eso es también fin.

Visto de este modo, el multiculturalismo no constituye una objeción teórica, porque es un simple hecho. Y este hecho, lejos de demostrar que los hombres que viven en sociedad no son amigos, manifiesta de modo evidente que tenemos un serio problema cuando no lo son. En el fondo, el (urgente) problema que plantea la diversidad cultural de las sociedades contemporáneas es el siguiente: ¿qué hacer cuando la sociedad no está ya constituida por conciudadanos que son tradicionalmente amigos, sino por personas ajenas a esa determinada tradición, con las cuales no parece haber nada en común y, por lo tanto, resulta casi imposible entablar una genuina amistad? Si concebimos la sociedad como el fruto de un acuerdo expreso entre parte irreductiblemente diversas, la cuestión se hace insoluble, porque entonces la misma diversidad inicial hace imposible todo acuerdo. En el fondo, el multiculturalismo es la concreción histórica del mito de una sociedad de individuos incomunicados; concreción que manifiesta radicalmente la insuficiencia de la respuesta moderna.

Con lo cual se responde también a la acusación de utopismo. La sociedad política no se puede fundar sobre un principio (tan falso e hipotético como su contrario) según el cual los hombres son buenos por naturaleza. Su fin, por lo tanto, tampoco puede ser la instauración del paraíso en la tierra. La tesis es, simplemente, que la sociedad política existe y funciona en la medida en que haya virtud y amistad entre sus miembros. Funciona muy bien si éstos son muy virtuosos, no tan bien si son malos, y deja de existir en el momento en que las costumbres se

Aquino, Buenos Aires, Argentina), N² 2, 2004, pp. 111-125, el cual demuestra cómo el nominalismo, en virtud del modo en que entiende la abstracción, hace inconcebible la dimensión contemplativa de los saberes, los cuales adquieren un carácter eminentemente práctico e instrumental.

80 Cfr. Aristóteles, Ética Nicomaquea, op. cit. (n.1), VI, 1141a 20-22 y T. Hobbes, OL, II, Praefatio al De Cive, p.142: "Dignissima certe scientiarum haec ipsa [i.e. philosophia civilis] est, quae ad Principes pertinet, hominesque in regendo genere humano occupatos". Vid también Strauss, Leo. "On the spirit of Hobbes's political philosophy". En su: Natural right and history, Chicago University Press, Chicago, 1953, republicado en Brown, Keith C. (ed.). Hobbes Studies. Oxford, Reino Unido: Blackwell, 1965, pp. 1-29, el cual nota explícitamente este punto (pp. 9-10).

81 Nuevamente, la cita es de la primera línea de Aristóteles, Politica, op. cit. (n.22), I, 1252a 1. 
corrompen por completo, porque no siendo posible la amistad entre los viciosos, deja de haber un mínimo principio de unidad en las conductas. Así como a cada régimen corresponde un modo de amistad ${ }^{82}$, a los regímenes totalmente corruptos corresponde su ausencia.

Allí donde lo común no puede ser instaurado por las voluntades, no queda más que intentar descubrirlo con las inteligencias. Es la tarea del derecho de gentes. Que la empresa no es estéril lo demuestra el hecho mismo de que, pese a todas las dificultades, la convivencia entre hombres radicalmente diversos es posible. Porque los hombres son amigos.

\section{CONCLUSIONES}

Las consecuencias de estas tesis son múltiples, y ameritan una atención que supera ampliamente los límites de esta exposición. Me limito a señalar aquellas que me parecen más relevantes para nuestro tema:

La sociedad politica es natural. O bien, el hombre es naturalmente social. Esto significa que incluso el más egoísta de los hombres quiere bienes comunes. El bien común no es el producto casual de una mano invisible que redirige praeter intentionem los intereses egoístas hacia el interés general, sino el objeto último de todo aquello que queremos. En este sentido, el deseo de los malos es contradictorio: hacen imposible el bien que ellos mismos manifiestan amar viviendo en sociedad, y precisamente por eso es lícito que la sociedad a la que pertenecen los castigue, porque el bien social contra el que atenta es también su propio bien.

Las sociedades existen porque sus miembros quieren que existan. Pero este querer no es una elección, sino una inclinación natural de la voluntad. De esta tesis, por lo tanto, no se sigue que la sociedad sea simplemente lo que nosotros queremos que sea. En otros términos: las sociedades se constituyen porque hay un cierto acuerdo fundamental sobre los modos comunes de obtener ciertos fines igualmente comunes, y el acuerdo se hace cada vez menos intenso mientras más se desciende a lo particular. Se trata, entonces, de un orden de amores, y no de una repetición de elecciones. Por eso, los principios fundamentales de una constitución se descubren al menos en la misma medida en que se deciden.

Cambiando la sustancia del acuerdo, cambia también la estructura del disenso. Existen ciertos acuerdos que son anteriores y fundantes respecto de cualquier disenso posterior. Lo diverso sólo existe en y por lo semejante. El mismo hecho del debate público manifiesta que queremos lo mismo (en el orden de los fines), aunque haya desacuerdo sobre el modo de obtenerlo (los medios). Al contrario, una total divergencia en los fines impide toda comunicación. Aquí radica la gravedad del discurso ideológico: en que es excluyente. Lo hemos visto con toda claridad precisamente en aquella ideología que se presenta a sí misma como abierta a toda postura disidente

82 Cfr. el paso ya citado de Aristóteles, Ética Nicomaquea, op. cit. (n.1), VIII, 1159b 25. 
(el liberalismo); lo hemos experimentado también en la ideología marxista y lo vimos durante este año 2011 en todas aquellas actitudes que se autojustificaban diciendo simplemente: "como tengo razón, puedo hacer lo que me parezca necesario".

El objetivo del debate público no es "ponerse de acuerdo", sino los bienes concretos y reales en cuestión. Al contrario, el vínculo social se funda sobre aquellas cosas en la que ya estamos de acuerdo, cosas que, por lo mismo, no se deben proponer, sino simplemente constatar.

Como decía un comentador de Tomás de Aquino, "la amistad está mucho más implantada en el corazón de la humanidad, mucho más confundida con lo humano, que la justicia" ${ }^{3}$. La justicia es un mínimo indispensable. Pero la sociedad política se funda en la amistad social y existe para realizarla plenamente.

\section{REFERENCIAS BIBLIOGRÁFICAS}

Agustín. Confesiones. Madrid, España: Biblioteca de Autores Cristianos, 2005.

Aristóteles. Le tre etiche. Milano, Italia: Bompiani, 2008.

Metafisica. En: Reale, Giovanni. Introduzione, traduzione e commentario della Metafisica di Aristotele. Milano, Italia: Bompiani, 2004.

Politica -3a edición-. Milano, Italia: Bur, 2008.

Berti, Enrico et al. Voz “entelechia”. En: Enciclopedia filosofica. Milano, Italia: Bompiani, 2006, pp. 3420-3423.

Воввіо, Norberto. “Il modello giusnaturalistico", En: Rivista internazionale di filosofia del diritto, 1973. pp. 603-622.

Thomas Hobbes. Torino, Italia: Einaudi, 1989.

Brown, Keith C. (ed.). Hobbes Studies. Oxford, Reino Unido: Blackwell, 1965.

Cassirer, Ernst. “Kant e Rousseau”. En su: Rousseau, Kant e Goethe. Roma, Italia: Donzelli, 1999.

Cicerón. Sobre la República y Sobre las leyes. Madrid, España: Akal, 1989

Derathé, Robert. Jean-Jacques Rousseau et la science politique de son temps. Paris, Francia: Vrin, 1988.

Derrida, Jacques. Politiques de la amitié. Paris, Francia: Galilée, 1994.

Diógenes Laercio. Vite e dottrine dei piú ilustri filosofi. Milano, Italia: Bompiani, 2005.

Dworkin, Ronald. Taking Rights Seriously. Cambridge (MA), Estados Unidos: Harvard University Press, 1978.

Faguet, Emile. Dix-huitième siècle. Études littéraires. Paris, Francia: Société Française d'imprimerie et de librairie, 1890.

Gentile, Francesco. Filosofia del Diritto (le lezioni del quarantesimo anno raccolte dagli allievi). Padova, Italia: Cedam, 2006.

Inteligencia política y razón de Estado. Buenos Aires, Argentina: EDUCA, 2008.

George, Robert. "Democracia, ley y persona humana”. En su: Moral Pública. Debates actuales. Santiago, Chile: Instituto de Estudios de la Sociedad, 2009.

83 Lachance, Louis. Humanismo político. Individuo y Estado en Tomás de Aquino. Pamplona, España: Eunsa, 2001, p. 440. 
Guerrero, Juan A. "Vínculos y ciudadanía en la Teoría de la justicia de John Rawls”. En: Villar, Alicia, et al. (ed.). Pensar la Solidaridad, Madrid, Espańa: Ediciones de la Universidad de Comillas, 2004.

Hoвbes, Thomas. Leviathan. Oxford, Reino Unido: Blackwell, 1946.

. The English Works of Thomas Hobbes of Malmesbury; Now First Collected and Edited by Sir William Molesworth. Londres, Reino Unido: John Bohn, 1839-1845.

Thomae Hobbes Malmesburiensis Opera Philosophica quae Latine scripsit Omnia, in unum corpus nunc primum collecta studio et labore Gulielimi Molesworth. Londres, Reino Unido: Joannes Bohn - Longman, Brown, Green et Longman, 1839-1845.

Jaume, Lucien. "Rousseau e la questione della sovranità. En: Duso. Giuseppe (ed.). Il potere. Per la storia della filosofia politica moderna. Roma, Italia: Carocci, 1999.

Kant, Immanuel. Filosofía de la Historia. D.F., México: Fondo de Cultura Económica, 1992.

. Ideas para una historia universal en clave cosmopolita y otros escritos sobre Filosofía de la Historia. Madrid, España: Tecnos, 1987.

—. La paz perpetua -6a edición-. Madrid, España: Tecnos, 1998.

- Lecciones de Ética. Barcelona, España: Crítica, 2009.

-. Metafisica dei Costumi. Milano, Italia: Bompiani, 2006.

Scritti politici. Torino, Italia: UTET, 1995.

Lachance, Louis. Humanismo político. Individuo y Estado en Tomás de Aquino. Pamplona, España: Eunsa, 2001.

Lamas, Félix Adolfo. "La concordia política" <En línea> [citado 15 de octubre de 2011]. Disponible en la World Wide Web: http://www.viadialectica.com/fil_estado.html.

. La concordia politica. Buenos Aires, Argentina: Abeledo-Perrot, 1975.

Machiavelli, Niccolò. Discorsi sopra la prima deca di Tito Livio. Milano, Italia: Bur, 1984.

Montaigne, Michel de. Ensayos. Madrid, España: Cátedra, 2005.

Morel, Jean. "Recherches sur les sources du Discours sur l'Inégalité", Annales de la société J.-J. Rousseau, No 5 , (1909), pp. 119-198.

Nietzsche, Friedrich. Humano, demasiado humano. Madrid, España: Akal, 1996.

Pirni, Alberto. "La Fondazione della Metafisica dei Costumi e il Regno dei fini: problema normativo e problema religioso in Kant". En: AA.VV. La trasmissione della filosofia nella forma storica. Atti del 33. Congresso nazionale della Società filosofica italiana, Genova, 30 aprile-3 maggio 1998, vol. 2: Comunicazioni e documenti. Milano, Italia: Franco Angeli, 1999, pp. 139-147.

Platón. República, Madrid, España: Gredos, 1992.

Polin, Raymond. La politique de la solitude. Essai sur la Philosophie politique de Jean-Jacques Rousseau. París, Francia: Sirey, 1971.

Rawls, John. "Justice as Fairness: Political not Metaphysical", en: Philosophy and Public Affairs, Vol. 14, No. 3. (Summer, 1985), pp. 223-251.

Rawls, John. A theory of justice (revised edition). Oxford, Reino Unido: Oxford University Press, 1999.

Political Liberalism. New York, Estados Unidos: Columbia University Press, 2005.

Rigobello, Armando (ed.). Il "Regno dei fini”. Napoli, Italia: Istituto italiano per gli studi filosofici, 1996.

Rousseau, Jean Jacques. Ouvres Complètes. Paris, Francia: Gallimard, 1959. 
Schmitt, Carl. El concepto de lo politico. En: Aguilar, Héctor Orestes (ed.), Carl Schmitt, Teólogo de la politica. D.F., México, Fondo de Cultura Económica, 2001.

Schwartz Porzecanski, Daniel. "Aquinas on Concord. 'Concord Is a Union of Wills, Not of Opinions", en: The Review of Metaphysics, Vol. 57, № 1 (2003), pp. 25-42.

Starobinski, Jean. "Jean-Jacques Rousseau et le péril de la réflexion", en: Annales de la Société Jean-Jacques Rousseau, No 34 (1956-1958), pp. 139-174.

. L'Oeil vivant. Paris, Francia: Gallimard, 1961.

La trasparence et l'obstacle. Paris, Francia:: Gallimard, 1971.

Strauss, Leo. "On the spirit of Hobbes's political philosophy". En su: Natural right and history. Chicago, Estados Unidos: Chicago University Press, 1953.

Tomás de Aquino, Comentario a la Ética a Nicómaco, Pamplona, España: Eunsa, 2000.

. Suma Teológica. Madrid, Espańa: Biblioteca de Autores Cristianos, 1954-1957.

Comentario a las Sentencias de Pedro Lombardo. Vol. II/2. Pamplona, España: Eunsa, 2004.

Vaughan, Charles Edwyn. The Political Writings of Jean-Jacques Rousseau. Cambridge, Reino Unido: Cambridge University Press, 1915.

Voegelin, Eric. "Order and History". En su: The Collected Works of Eric Voegelin. Columbia, Estados Unidos: University of Missouri Press, 2000, vol. 16.

Widow, Juan Antonio. "La universalidad de la norma y la filosofía práctica", en: Revista Internacional de Filosofia Práctica (Instituto de Estudios Filosóficos Santo Tomás de Aquino, Buenos Aires), N²2, 2004, pp. 111-125. 